\title{
HARLEY QUINN: DE SIDEKICK A HEROÍNA ANÁRQUICA ${ }^{1}$
}

\author{
Marcos Rafael Cañas Pelayo²
}

\section{Harley Quinn: De sidekick a heroína anárquica}

Resumen: La evolución del personaje de Harley Quinn es una de las más interesantes en el cómic norteamericano. Creada por Paul Dini y Bruce Timm para una serie animada sobre Batman, Harley pasaría pronto de ayudante de un villano como el Joker a convertirse en una de las figuras más reconocibles del universo DC, presente en muchos medios (televisión, videojuegos, cine...). Su personalidad se ha ido enriqueciendo a través de sus distintas versiones. Con un punto de partida que la situaba como víctima de una relación tóxica, actualmente representa una heroína de popularidad en auge con su próxima película anunciada para 2020.

Palabras clave: Anarquía, Compañera, Emancipación, Merchandising, Relación tóxica.

\section{Harley Quinn: From sidekick to Anarchic Heroine}

Abstract: The evolution of Harley Quinn's character is one of the most interesting in the American comic. Created by Paul Dini and Bruce Timm for Batman: The Animated Series, Harley would soon go from a sidekick to a villain like the Joker to become one of the most recognizable figures in the DC universe, present in many media (such as television, video games, movies...). Her personality has been enriched through its different versions. With a starting point that placed her as the victim of a toxic relationship, she currently represents a booming popularity heroine with her next film announced for 2020.

Key words: Anarchy, Sidekick, Emancipation, Merchandising, Toxic relationship.

\section{A modo de introducción: Una sidekick con voz propia}

A pesar de no alcanzar todavía las tres décadas de existencia en el universo DC ${ }^{3}$, en comparativa con otros compañeros/as de mayor recorrido a lo largo del tiempo en la editorial, Harley Quinn es uno de los personajes más reconocibles de dicha franquicia en la actualidad (Pardo y Monje 2016: 33). Hazaña nada pequeña si se tienen en cuenta los modestos orígenes que precedieron su creación.

\footnotetext{
${ }^{1}$ Fecha de recepción: 06/09/2019. Fecha de aceptación: 02/12/2019.

${ }^{2}$ Doctor Europeo por la Universidad de Córdoba. Profesor de Geografía e Historia en el IES Maimónides, Córdoba, España; $\square$ capemarcos@ hotmail.com correo electrónico.

${ }^{3}$ Editorial de cómics norteamericana. Forma parte de la empresa DC Entertainment, además de tener una salida cinematográfica para sus creaciones a través de la productora Warner Bros.
} 
Encarnada hoy para la gran pantalla por la popular actriz australiana Margot Robbie (Fente y Fernández 2016: 40), la primera aparición de Harley la hallamos en el capítulo número 22 de Batman: The Animated Series, emitido un 11 de septiembre de 1992 (Pardo y Monje 2016: 33-34). Si bien era un programa orientado para el público infantil, esta versión animada del célebre cómic terminaría logrando respaldo por parte de crítica y espectadores/as, al captar con inteligencia la esencia del superhéroe creado por Bob Kane y Bill Finger, ofreciendo distintos niveles de visionado que permitían mantener asimismo el interés del sector adulto de la audiencia (Hernando 2004: 205206).

Aquella entrega fue titulada "El favor del Joker", indicativo de que el show volvía a utilizar al célebre payaso criminal que es reconocido universalmente como la gran némesis de Batman. Una de las cuestiones que más llamaron la atención del episodio fue una figura femenina disfrazada de arlequín, miembro destacada de la banda del villano (Johnson 2017: 82). A diferencia de otros miembros de la misma, se nos revelaba su nombre, Harley, además de quedar claro que tenía una estrecha relación con el adversario del héroe.

Los responsables de la incorporación de este personaje fueron el guionista Paul Dini y Bruce Timm, diseñador y productor principal del programa, quienes únicamente querían hacer un homenaje a la serie televisiva Batman (1966-1968), protagonizada por el actor Adam West. Plagado de estética camp ${ }^{4}$, el show desvirtuaba mucho el trágico origen del justiciero de la ficticia ciudad de Gotham, pero sí logró ingresar en la cultura popular estadounidense (Hernando 2004: 98-99).

\footnotetext{
${ }^{4}$ Se conoce así a la estética que emplea mucho humor, banalidad y colorido de formar hiperbólica. 
En ese espacio televisivo era frecuente que los villanos que se medían a la pareja protagonista, Batman y Robin, tuvieran varios esbirros. Ocasionalmente, existían algunas adláteres femeninas que apoyaban al antagonista (Desris 2016). Probablemente, en el caso del Joker la más relevante fue Queenie, la homonimia no parece casual, interpretada por la actriz Nancy Kovack en los episodios 5 y 6 de la primera temporada. Con cabello rubio, sentido del humor y absoluta devoción por el criminal, parece indudable que dejó un impacto en la memoria de Dini y Timm para diseñar al nuevo personaje (Beard 2011).

Existía asimismo una excepción en la serie de los 60 del pasado siglo, una villana con rango propio y líder de su organización criminal, Catwoman. Un personaje surgido como homenaje a la célebre femme fatale de tantas novelas pulp y películas de cine negro (Hanley 2017: 17-20). Se trata de un caso bastante extraordinario para la mentalidad televisiva machista de la época, al no depender de ningún superior masculino para sus planes. Naturalmente, Selina Kyle, identidad civil de la célebre ladrona de Gotham, tuvo cabida en la versión animada que comentamos, pero Dini y Timm variaron poco su personalidad con respecto a los cómics. La ventaja con Harley era poder contextualizarla desde un punto de partida dependiente para hacerla alcanzar autonomía, además de ser totalmente novedosa, sin tener que respetar una continuidad previa.

Con todo, su primera aparición bien pudo ser la última, el simple homenaje a un programa predecesor. No obstante, varios elementos permitieron a aquella acrobática delincuente sobrepasar dichas expectativas. A la hora de hacer los primeros bocetos, Dini recomendó a su equipo tener como referencia la caracterización que Arleen Sorkin había hecho de un bufón en una escena onírica de la serie Days Of Our Lives. Sorkin y 
Dini se conocían desde sus días de instituto, por lo que la intérprete se mostró interesada en la oferta de doblar a personaje de Harley (Pardo y Monje 2016: 34). Desde el principio, supo captar un punto de humor negro no exento de ternura que dio mucha entidad propia a la recién llegada a la serie. Harley iba escalando en popularidad y la audiencia demandaba más apariciones suyas (Johnson 2017: 84).

Tabla I. Primeras apariciones de Harley Quinn en Batman: The Animated Series

\begin{tabular}{|l|r|r|}
\hline & Título del episodio & Papel de Harley Quinn \\
\hline Capítulo 22 & Joker's Favor (1992) & Presentación del personaje \\
\hline Capítulo 34 & The Laughing Fish (1992) & Rol muy secundario \\
\hline Capítulo 46 & Almost Got'Im (1992) & Ayudante del Joker \\
\hline Capítulo 51 & The Man Who Killed Batman (1993) & Alianza con Poison Ivy \\
\hline Capítulo 68 & Trial (1994) & Forzada colaboración con Batman \\
\hline Capítulo 72 & Harlequinade (1994) & Primer intento de reformarse \\
\hline Capítulo 81 & Harleýs Holiday (1994) & \\
\hline
\end{tabular}

Fuente: Batman the complete Animated Series: Deluxe Limited Edition

Mención aparte merece la labor llevada a cabo por la compositora Shirley Walker, quien logra captar musicalmente las paradojas que rodean a Harley (Johnson 2017: 8485). Por un lado, sonidos cartoon $^{5}$ divertidos y ágiles que pueden cambiar súbitamente a tintes dramáticos en algunas confrontaciones contra el Joker cuando manifiesta síntomas de rebeldía.

Existe debate sobre este debut. Algunos análisis del capítulo estiman que no puede considerarse que posea un rango superior al resto de los esbirros del Joker,

\footnotetext{
${ }^{5}$ Se conocen con ese término en Estados Unidos a las series o películas de dibujos animados, así como un tipo de historieta que recrea dicha estética. Las tiras cómics de Daredevil de Lev Gleason Publications en la década de los 40 del pasado siglo fueron una gran influencia para Bruce Timm en sus diseños.
} 
aunque no niegan el nivel de carisma que alcanza Harley debido a su dobladora (Johnson 2017: 84-85). No obstante, en otros casos se acentúa que desempeña una función aparte, una parodia del fenómeno del fanboy o la fangirl de un personaje o saga, hasta el punto de customizar su propio vestuario (Fente y Fernández 2016: 34).

Tal vez la forma más adecuada de referirnos a ella en esos instantes iniciales sea como sidekick, expresión anglosajona que se utiliza, especialmente en los cómics, para hacer referencia al compañero/a que un héroe o heroína principal poseen. La única diferencia es que Harley lo haría con respecto a un villano. Faceta ingrata, puesto que el porcentaje de éxito en ese grupo resulta escaso (Morris 2018), si bien estamos ante una de las más notables excepciones a esa regla.

Desde una perspectiva de género, podemos identificar también que esta primera versión de Harley tiene un claro componente de objeto de deseo masculino. De igual forma ocurre con su debut en el medio de los video-juegos, incluso de manera mas acentuada, como veremos en el epígrafe correspondiente. Una cosificación de la que Harley Quinn terminaría logrando escapar gracias a la profundidad alcanzada en tratamientos posteriores de su personalidad y motivaciones.

A pinceladas en las siguientes entregas televisivas, iban revelándose cuestiones sorprendentes sobre el personaje, quien se desmarcaba por completo del resto de subalternos del Joker, generando una gran curiosidad en el público. Llegado el momento, Paul Dini y Bruce Timm desvelarían todas las cuestiones alrededor de Harley Quinn, cambiando totalmente la percepción que se tenía sobre la alegre villana (Barba y Perrin 2017). 


\section{Mad Love: El Rubicón de Harley Quinn}

La creciente fama de la serie animada convenció a DC de aprovecharla en otros medios. Comenzando por una serie de cómics titulada The Batman Adventures que continuaba y enriquecía esta versión sobre el héroe. El propio Bruce Timm encabezaba asimismo algunas miniseries y números especiales donde podían desarrollar gran autonomía creativa y dar pasos más osados que en un programa para todas las edades, firmando una historia sobre el personaje de Dos Caras que alcanzó un gran éxito de crítica (Hernando 2004: 223-225).

Tanto Dini como Timm estaban convencidos de que debía hacerse un monográfico sobre Harley donde encajasen todas las pistas sobre su origen. En 1994 el misterio de su pasado quedó desvelado en un número especial titulado Mad Love, una trama a tres bandas entre Harley, el Joker y Batman, aunque la primera sería la verdadera protagonista.

Si bien la cadena FOX estaba complacida con el producto televisivo, mantenía una férrea censura cada vez que el programa intentaba adentrarse en territorios de temática más sombría (Hernando 2005: 18-20). El Joker y su verdadero nivel de maldad eran una de las obsesiones de los guionistas, quienes querían recuperar las intenciones siniestras que le rodeaban desde su primera aparición en las tiras de cómics de 1940.

Durante muchas décadas, Bob Kane hurtó a Bill Finger, su guionista, el mérito de la autoría de este enloquecido criminal, si bien hoy ya es un hecho reconocido que la personalidad del reverso oscuro de Batman fue concebida por el escritor (Hernando 
2014). A diferencia de otros antagonistas, el Joker no se contentaba con el robo o ascender en la mafia, sus propósitos eran la destrucción burlesca en sí misma, un generador de caos.

Poco después de la II Guerra Mundial, fruto de la difusión alarmista de los trabajos del doctor Fredric Wertham, se impuso en Estados Unidos el Comics Code, un mecanismo de control censor que procuraba suavizar los contenidos de las viñetas, evitando especialmente aquellos más violentos, sexuales o temas sociales controvertidos (Cañas Pelayo 2017: 79). Esto se tradujo en varios fenómenos como el retroceso del papel de heroínas con la importancia de Wonder Woman (McCausland 2017: 80) o la suavización de villanos como el Joker, quien pasaba de ser un peligroso psicópata a un pintoresco rufián sin más notoriedad que su estética circense.

Las aguas volvieron a su cauce en 1973 con la aventura titulada "The Joker's Five-Way Revenge”, firmado por el guionista Dennis O’Neil y el dibujante Neal Adams. Se trataba de un relato detectivesco donde Batman debía seguir la pista de los asesinatos que su adversario estaba haciendo con antiguos lugartenientes que le delataron. O’Neil fue uno de los escritores con los que Dini y Timm se entrevistaron para decidir cómo tratar de mostrarlo en televisión (O`Neil 2008).

El Joker de Batman: The Animated Series no mataba directamente, pero quedaba claro en varios episodios que estaría dispuesto a hacerlo. Su gas de la risa ya no era una burla de estilo camp, se trataba de un producto químico capaz de alterar de forma grotesca y desfigurar las facciones de sus víctimas. Para dejar patente la maldad del payaso, su relación con Harley Quinn sería el vehículo perfecto. 
Mad Love desvela que Batman lleva tiempo investigando sobre la eficaz nueva edecán del delincuente, compartiéndose por primera vez con el público sus resultados. Se descubría en el número que su nombre real completo era Harleen Quinzel, quien había sido una destacada gimnasta amateur hasta el punto de lograr una beca para la universidad de Gotham. Sus años en el campus reflejaron que sus metas iban más allá de las hazañas deportivas, doctorándose en Psicología. No obstante, de forma sutil se ve en las viñetas de flashback que no dudó en aprovecharse de su atractivo para lograr la máxima calificación por su tesis.

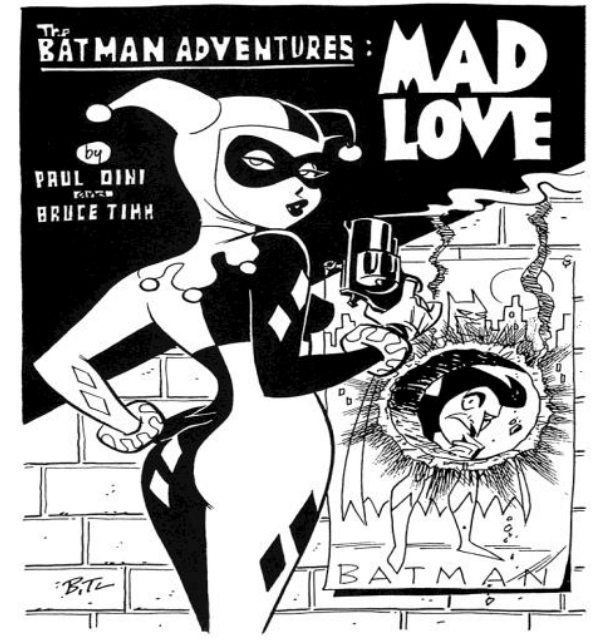

Fig. I. Portada alternativa de Mad Love (febrero 1994)

Buscando reforzar esos recuerdos, el guión de Paul Dini completa los vacíos de la investigación de Batman con soliloquios de Harley, quien culpa al Murciélago de la mala situación que atraviesa su relación con el Joker. Rememora su primer día en 
Arkham Asylum, el sanatorio mental donde se interna a las personalidades criminales más enloquecidas de Gotham.

Como su propia supervisora, la doctora Leland, advierte, resulta curioso que la joven doctora con altas calificaciones tuviera curiosidad por iniciarse en un trabajo tan duro, cuando sus recomendaciones le habrían valido puestos más remunerados y con consultas menos peligrosas. Tanto la principal responsable de Arkham como el Joker comprenden que la recién llegada se inicia con una idea romántica y errada del tipo de casos que va a tratar, confesando que ve mucho glamour e idolatría en los/as residentes más célebres por sus peculiares delitos. No obstante, mientras la primera intenta prevenirla con prudentes consejos, el segundo inicia un inteligente juego de manipulación para ponerla de su lado.

Desde sus primeras entrevistas, el recluso logra ir cambiando la perspectiva de la interesada doctora, incluso sugiriéndole que puede combinar su nombre para formar la palabra "Harlequin". Es el germen del que será su futuro alias criminal, añadiendo el Joker que escenificaría "El espíritu puro de la diversión y la frivolidad". Al detectar ese interés, Leland intenta disuadirla sin éxito de hablar con él.

Lejos de comportarse cómo le conoce la audiencia en la serie de animación, Dini y Timm muestran a un Joker que confiesa haber sufrido maltrato físico por parte de su padre en la niñez. En apenas unas páginas, se ofrece una perspectiva diferente del antagonista, quien combina ternura y humor para revelar secretos muy personales a su nueva doctora, en quien parece confiar plenamente. En realidad, estamos ante un cómic de apariencia juvenil que muestra con maestría el grado de manipulación que puede llegar a ejercer otra persona sobre las buenas intenciones de otra (Hernando 2005: 74). 
Mad Love tenía como propósito lograr una fuerte empatía entre el público y Harley, haciendo comprender a la audiencia del show que ella pensaba estar obrando correctamente en defensa de la persona amada ante un Batman al que imagina en esas sesiones como la encarnación de un mal nefasto y opresor contra una torturada alma libre. Cia Jackson ha firmado un interesante ensayo donde incide en la capacidad de esta obra para que nos proyectemos desde ese punto de vista de Harley (Barba y Perrin 2017: 20).

Las primeras pistas sobre la red de mentiras se detectan cuando el Joker adultera la memoria de su primer crimen para responsabilizar por completo a su adversario; para ese momento, Timm dibuja a Harley ya sentada en la mesa de paciente y al recluso como improvisado psiquiatra.

De vuelta al presente de la historia, observamos que Harley toma la iniciativa para ayudar a su frustrado amor. No solamente ejecuta de forma brillante un antiguo plan del payaso, añade una serie de elementos al mismo que logran una trampa para que Batman caiga prisionero y completamente a su merced (Dini y Timm 2015). Mientras espera la llegada de su enamorado para ofrecerle en bandeja de plata a su gran adversario, El Murciélago tendrá la oportunidad de entablar un diálogo con su captora donde logra analizar con habilidad las manipulaciones a las que ha estado sometida. De forma convincente, el prisionero deja claro que el Joker juega con habilidad con distintos posibles pasados, según su auditorio, logrando una fuerte empatía para arrastrar a otras personas a hacer lo que él desea.

No es infrecuente que en personajes ficticios con larga andadura haya distintas versiones sobre su origen, en ocasiones, muy contradictorias entre sí. El mérito del 
guión de Dini es que esas incoherencias son explicadas por la propia inteligencia del villano, quien es capaz de discernir correctamente qué tipo de motivaciones pueden hacerle más simpático frente a la persona que le brinda su confianza. El propio Christopher Nolan en su trilogía cinematográfica sobre Batman no se resistiría a utilizar esta táctica del payaso. Recientes estudios definen este recurso como el arma arrojadiza de la no-identidad (Álvarez 2018: 116-118).

Una de las cuestiones Mad Love quiere dejar claro es no insultar a la inteligencia de Harley y dejar futuras posibles opciones de salida para el personaje, cara a los proyectos que tenían con ella en la serie. Queda patente por sus gestos que comprende el razonamiento de Batman sobre los engaños a los que ha sido sometida, terminando por armar un escudo defensivo negacionista donde culpa al justiciero de los actos de su pareja, a quien apoda cariñosamente, igual que en el programa televisivo, "pastelito".

Cia Jackson ha incidido en que aquí se refleja cómo los ideales del romanticismo novelesco pueden ser empleados perversamente para doblegar la individualidad en aras de la sumisión (Barba y Perrin 2017: 19-20). Imaginando la dulce vida que les aguarda una vez hayan eliminado a Batman, vemos que las fantasías y anhelos de Harley han cambiado. Quien fuera una ambiciosa atleta y psicóloga con proyección, se visualiza feliz en un hogar al servicio del Joker, quien aguarda con su pipa a que ella sirva la cena ante el alboroto de una pareja de críos que han tenido. Timm satiriza aquí el estereotipo familiar que tantas veces se ha perpetuado en las series televisivas.

Su lenguaje con el Joker jamás es casual, puesto que combina los cariñosos apelativos en privado con un respetuoso "señor J" cuando se encuentran con otros miembros de la banda. Es decir, sentimientos nada correspondidos que escenifican la 
toxicidad del vínculo. Pensando que con Batman fuera de la ecuación tendrán un futuro juntos, Harley espera impaciente su llegada. No obstante, el fácil triunfo que le ha brindado se torna en tragedia.

El Joker irrumpe en estado de frenesí y herido en su amor propio porque otra persona logre aquello de lo que él ha sido incapaz. En su mente imagina las burlas que otros jefes criminales del hampa de Gotham harán sobre su figura por haber sido su novia la verdadera vencedora. Queda patente su maltrato psicológico y físico a su pareja, incluso dentro de los rigores censores de este tipo de publicación. Esto terminará propiciando la posibilidad de fuga de Batman, además de poner de manifiesto el enfermizo orgullo de su rival, quien además es el culpable de una terrible caída de Harley desde las alturas de su guarida. Bruce Timm, siempre abonado a la estética cartoon para suavizar los momentos más violentos de la narración (Nolen-Weathington, 2012), no usa esa solución para este instante, sin caer tampoco en la recreación morbosa. Observamos las linternas de la policía, mientras llaman a una ambulancia para Harley Quinn, intuyéndose el reguero de sangre y las graves heridas que ha sufrido.

Pese a que el Joker es derrotado finalmente por Batman, el epílogo de Mad Love es terrible. De alguna forma, el villano logrará filtrar una pequeña nota autógrafa donde desea una pronta recuperación a la hospitalizada Harley, quien se ha jurado instantes antes terminar con esa relación. No obstante, el mensaje la hace volver a plantearse que su romance tiene futuro.

La crítica reconoció la calidad de Mad Love con los prestigiosos premios Eisner y Harvey en el año de 1994 en la categoría de mejor historia unitaria. La popularidad de 
Harley Quinn seguía creciendo, además de haber alcanzado una complejidad trágica. Justo el punto perfecto para que diera un paso adelante.

\section{El camino a la emancipación}

"Esta fue una decisión importante, porque al aparecer siempre al lado del Joker es imposible desmarcarse de sus rasgos neuróticos. Sin embargo, situarla en frente de un personaje fuerte como Poison Ivy era mucho más natural y permitiría lucirse a Harley”. Con estas declaraciones de Bruce Timm (Pardo y Monje 2016: 34), queda de manifiesto una de las necesidades que el equipo creativo de Batman: The Animated Series había detectado: evitar limitar al personaje de Harley a su relación con el Joker.

A diferencia de antagonistas como El Acertijo o El Pingüino, Poison Ivy era una enemiga de Batman con legítimas motivaciones. Debiendo sus poderes a los excesos de la ciencia y experimentaciones sin cautela de las que fue víctima, la botánica Pamela Lillian se convierte en la poderosa Poison Ivy, capaz de tener un control excepcional sobre la flora a su alrededor. Concebida en la década de los 60 del pasado siglo, los problemas de contaminación actuales han reforzado la percepción sobre esta adversaria de Batman, cada vez más concebida como una firme defensora de la naturaleza, ubicándose el problema en que no repara en utilizar medios radicales para lograr protegerla.

Igual que en su versión para el cómic, la Poison Ivy de la serie animada pronto ocupó un lugar preferencial en el panteón de rivales del protagonista. Su fuerza, 
ecologismo e independencia la convertían en una compañera de aventuras muy interesante para Harley (Johnson 2017: 426). Nuevamente el tándem Dini-Timm se dispuso a hacer un segundo monográfico en cómic donde Ivy y Harley serían las estrellas, sin la presencia del Joker y con Batman relegado a un papel muy secundario (Dini y Timm 2016).

Con una clara inspiración en el género cinematográfico de la road movie ${ }^{6}$, especialmente la película Thelma \& Louise (1991), Dini y Timm querían embarcar en una montaña rusa a la improvisada pareja. Pese a que el guionista terminó de escribir el argumento con rapidez y buscando aprovechar la popularidad de Mad Love (Hernando 2005: 66-67), los nuevos proyectos de animación que la Warner estaba haciendo llegar a Bruce Timm le retrasaron mucho a la hora de dibujarlo, algo que influyó en que tuviera menor recepción que el anterior.

Usando con habilidad el slapstick ${ }^{7}$, Harley \& Ivy es una divertida historia en tres números donde la improvisación anárquica de la primera choca frecuentemente con el pragmatismo de la segunda. Incluso hay momentos para la metaficción, como cuando Harley utiliza el dinero de un botín para rodar una película sobre Batman donde le mata sistemáticamente y con muchas explosiones. No se escapa el hecho de que, más allá del gag en sí, era una crítica a las adaptaciones cinematográficas del héroe en la década de

\footnotetext{
${ }^{6}$ Películas donde una pareja con personalidades distintas hace dos viajes en uno. Por un lado, el destino real al que van y, en segundo y más interesante término, uno interior que les permite conocerse mejor mutuamente. Recientemente, Timm volvió a reunir a esta pareja para la película animada Batman and Harley Quinn (2017). En esta ocasión, Quinn intentaría salvar a Ivy de un peligroso proyecto en el que se está embarcando, formando alianza con su antiguo enemigo. Los títulos de crédito de este film fueron un homenaje a la célebre saga cómica de La Pantera Rosa de Blake Edwards, en una aventura ligera y repleta de gags con mucho protagonismo de Harley, doblada en esta ocasión por Melissa Rauch, idónea para el papel por su experiencia en la comedia de situación The Big Bang Theory. Esta versión de Quinn no solamente aporta comedia, puesto que es su conocimiento de los métodos de Ivy la que permite salvar la situación para Gotham, siendo co-protagonista en todo momento de Batman.

${ }^{7}$ Forma de referirse a la comedia física, basada en los golpes, carreras, tropezones, etc. Puede tener un aire irreal o inverosímil, especialmente en el género de la animación.
} 
los 90, especialmente las dos últimas dirigidas por Joel Schumacher: Batman Forever (1995) y Batman y Robin (1997). De hecho, el propio cineasta admitió que en dichas entregas se había banalizado mucho al personaje y el entorno de Gotham, cayendo en el mero entretenimiento espectacular sin contenido, por lo que planteó una frustrada secuela que iba a tener un tono más sombrío. Mark Protosevich fue el guionista encargado de firmar Batman Unchained, donde por primera vez iba a aparecer Harley en la gran pantalla (Fente y Fernández 2016: 37).

En el libreto se adulteraba el origen de la villana, quien quedaba convertida en hija del Joker, fallecido en la primera parte dirigida por Tim Burton (1989). Schumacher quería dirigir una secuela donde Harley recibiría el apoyo de Jonathan Crane, un brillante psicólogo que se aprovechaba sus conocimientos de los miedos y fobias para aterrar a sus víctimas en aras de una venganza contra el protagonista.

Con todo, al ser cancelada la franquicia por el momento, a Harley todavía le quedaba más de una década para estrenarse en el celuloide, lo cual no quitaba que estuviera en un momento de bonanza creativa por su creciente importancia en Batman: The Animated Series. "Harley's Holiday", escrito por Paul Dini, daba un paso más allá en la emancipación del personaje de sus orígenes (Johnson 330-333). Tras mantenerse rehabilitada y alejada de las influencias criminales, recibiría una oportunidad de reincorporarse a la vida civil tras cumplir condena en Arkham.

Como en anteriores ocasiones, tras la estética colorida, se escondía una reflexión social profunda. Este episodio con ella como gran protagonista refleja los problemas de una persona que ha cumplido su deuda con la sociedad, pero sigue sufriendo el recelo de 
los demás, quienes siguen considerándola una delincuente. Un malentendido en una tienda terminará con una alterada Harley obligada a fugarse.

Curiosamente, mientras que el primer guardia jurado del establecimiento es razonable y da el beneficio de la duda a la recién liberada, conforme el asunto se desboca y cae en autoridades superiores se toman decisiones hiperbólicas. Lejos de entender que tratan con alguien al borde de una crisis nerviosa por el percance, las fuerzas del orden de Gotham aplican un protocolo de supervillana absolutamente innecesario y perjudicial.

En su huida, Quinn tomará involuntariamente como improvisada rehén a Verónica Vreeland, pareja de Bruce Wayne (identidad real de Batman) quien terminará teniendo síndrome de Estocolmo con su captora. A diferencia de Mad Love, aquí Dini utiliza un recurso inverso para plantear un final esperanzador pese a que termine siendo arrestada: Batman acude a Arkham para confiar a Harley que es consciente de que no había incurrido en ningún delito y le promete apoyo para terminar logrando reinsertarse.

El éxito de la serie se tradujo en una continuación titulada The New Batman Adventures (1997-1999). Para explicar la importancia alcanzada por Harley, baste manifestar que únicamente el Joker la superó en apariciones dentro del elenco de secundarios (Pardo y Monje 2016: 35). De hecho, el 16 de enero de 1999 se estrena "Mad Love", fiel versión animada del célebre cómic (Dini y Kidd 2016).

DC Comics ya estaba convencida plenamente de que Harley Quinn merecía hacer aparición en la colección oficial y primera de Batman, incorporándola de pleno derecho 
en su principal universo. Para ello se aprovechó el crossover $^{8}$ conocido con el nombre Tierra de nadie. Arrancada en octubre de 1999, era una ambiciosa saga donde todo se originaba por un terremoto que dejaba a Gotham al borde de la extinción y sin recibir apoyos externos. Esto hacía sacar lo peor y mejor de su ciudadanía, además de poner a los héroes y heroínas de la misma ante una adversidad que no podía resolverse simplemente con una pelea: habrían de hacer frente a un desastre natural, además de a sus consecuencias físicas y psicológicas (Hernando 2004: 235-241).

Concebida con una técnica muy similar a la propia de la novela río, Tierra de nadie va contando las historias de distintos personajes y también de gente anónima para explicar la nueva situación en Gotham. Un número especial sobre el evento fue Batman: Harley Quinn, publicado en octubre de 1999, donde Paul Dini iba, en compañía de dibujante Yvel Guichet, a incorporar a Harley a esa continuidad. Todo comienza cuando Poison Ivy, quien avanza en un carruaje buscando entre los escombros de la urbe, se encuentra con una accidentada figura a la que pronto identifica como la doctora Quinzel a quien conoció durante su estancia en Arkham.

Conducida a un refugio seguro, Harley comienza a explicar a su anfitriona qué la ha llevado a ir vestida como un arlequín. En muchos sentidos, Dini mantiene los elementos de Mad Love, aunque hay alteraciones significativas. Se obvia el pasado como gimnasta de la villana y también que lograse mejorar sus notas seduciendo a miembros de su departamento universitario. Mientras que la primera parece una omisión innecesaria (de hecho, Poison le ayudará con compuestos químicos de su creación a aumentar su agilidad, cuando hubiera sido más sencillo justificar sus acrobacias por su

\footnotetext{
${ }^{8}$ En los cómics, cuando personajes de una colección se mezclan con los de otra, desarrollando una trama cuyo peso se reparte entre las distintas cabeceras.
} 
pasado como atleta), el segundo punto sí representa una interesante modificación que, además, justifica sus conocimientos de psicología e inteligencia.

Eso no quiere decir que se presente a una Harley exenta de defectos. Pronto, se descubre que ingresó en Arkham buscando coleccionar una serie de entrevistas a asesinos en serie que le permitirían redactar un libro morboso y superventas. Cia Jackson ha subrayado la importancia de esta faceta que sería explotada en el futuro, la de una Harley vinculada al merchandising de su propia figura en grado extremo (Barba y Perrin 2017: 16-29). Nuevamente, en sus entrevistas con el Joker terminaría cayendo en sus redes. De manera aguda, Guichet combina la visión idealizada del romance que cuenta Harley con las sensatas dudas que va planteando Poison Ivy, quien intuye muy bien la realidad tras las manipulaciones.

Habrá un nuevo enfrentamiento a tres bandas entre ella, Batman y el Joker que no tiene la complejidad alcanzada en Mad Love. Siendo una buena presentación para el personaje en los cómics oficiales, deja la sensación de ser una visión bastante simplificada del verdadero origen (Pardo y Monje 2016: 35).

\section{Supervivencia antes del estrellato}

Dentro del universo DC, ningún personaje ha tenido un origen más vinculado al feminismo que Wonder Woman, debido a la especial sensibilidad por la cuestión de su equipo creativo (Lepore 2015). Asimismo, ya hemos mencionado en este artículo que en la propia colección de Batman encontramos a Catwoman, cuya condición de rival del héroe le permitía escapar de varios de los tópicos asociados al tratamiento de la figura femenina en este medio (Hanley 2017: VII-VIII); por ejemplo, en comparativa con Lois 
Lane, pareja de Superman, quien tardaría más tiempo en recibir el reconocimiento que merecía (Hanley 2016).

Recientemente, con el creciente interés por el género superheroico, estamos asistiendo a interesantes disertaciones sobre el papel del género en este apartado de la ficción (Goodrum, Prescott y Smith 2018). Se trata de un campo de estudio plagado de posibilidades, porque ver cómo han sido representadas las superheroínas y las villanas en la cultura popular aporta claves sociales, culturales y antropológicas que desvelan el contexto donde se gestaron (Cocca 2016).

Como han expuesto de forma clara Scarlett Harrington y Jennifer A. Guthrie, uno de los temas de más relevancia está encarnado de forma casi perfecta por Harley Quinn: la violencia de pareja, un tema casi tabú en las viñetas estadounidenses durante décadas (Barba y Perrin 2017: 55-69). Es cierto que encontramos un precedente importante en los cómics Marvel, concretamente en la figura de Janet Van Dyne, La Avispa, quien en 1981 separaba camino con su pareja, Hank Pym, tras sufrir maltrato, convirtiéndose en poco tiempo la primera líder del supergrupo Los Vengadores, plaza que hasta ese momento parecía reservada para los miembros masculinos (Salazar 2000: 71-72).

En el caso de Harley, a todo ello sumaba comenzar fuera de la ley, por lo que su reto era doble: salir de la situación de la que era víctima y abandonar sus antiguas actividades delictivas. Willmaria C. Miranda lo ha definido de manera elocuente: "Un nuevo tipo de líder: la complejidad de sobrevivir al abuso y convertirse en una heroína" (Barba y Perrin 2017: 84-92).

A este respecto hemos de tener cuidado con el empleo de dicha terminología. ¿Qué connotaciones tendría el calificativo de heroína? Los grandes medios de masas, 
especialmente cine y televisión, perpetuaron durante décadas una división de roles donde el héroe tradicional debía salvar a su compañera en última instancia, estereotipando la perspectiva de la "damisela en apuros".

Recientes líneas de investigación, están optando por formulas como "héroe femenino" o simplemente "héroe" que acentúen el papel activo ejercido por la protagonista de esos relatos. En nuestro artículo, optamos por denominar a Harley como heroína, entendiendo que aplicamos la connotación actual y no la de anteriores épocas donde tendría un sentido de disminución de su capacidad de actuación con respecto a los personajes masculinos.

DC Comics le dio su primera colección propia que estuvo vigente entre octubre del año 2000 y noviembre de 2003 (Pardo y Monje 2016: 36-37). La serie mantuvo la línea de alejar a Harley de la figura del Joker. Dubitativa entre pasar al lado de heroínas como Batgirl o mantener sus antiguos hábitos, se trató de una colección con tono humorístico que tuvo un importante descenso de ventas a partir del número 26, fruto de los constantes cambios de equipos artísticos.

Si desde su primera aparición en el show televisivo animado Harley estaba acostumbrada a gozar del favor del público, la cancelación de esta serie supuso un duro revés para su popularidad a comienzos del nuevo milenio, quedando arrinconada en papeles muy secundarios de otras colecciones.

Hay alguna excepción honrosa como su aparición en la saga Hush, guionizada por Jeph Loeb a lo largo del año 2002, un evento que homenajea obras como La carta robada de Edgar Allan Poe, pero dentro del universo de Batman. Es decir, un misterio 
que se va complicando. Buscando revelaciones, el protagonista se las verá con una larga nómina de rostros conocidos, incluyendo el de Harley.

El artista Jim Lee admitió sentir dudas con respecto a su formar de dibujarla, reflejando una de las dificultades que tenía el personaje: pocos miembros del equipo artístico de DC, a excepción de la serie animada, estaban acostumbrados a tratar con un personaje tan novedoso (Serradilla 2008: 63-64). Con todo, Lee firmó un trabajo notable donde Harley tenía un espectacular duelo con Catwoman en plena representación de la ópera Pagliacci. Con referencias que van desde el cine de los hermanos Marx a la música clásica, Hush permite recuperar su versión más divertida.

Desafortunadamente, los otros cameos y apariciones del personaje no tendrían esa trascendencia. Habría de esperar hasta el verano de 2007, cuando Paul Dini nuevamente vuelva a recuperarla en Detective Comics \# 831, una aventura inusual donde es más protagonista Bruce Wayne que su identidad secreta como Batman. Miembro destacado e inversor de Arkham, Wayne vota de forma negativa para la condicional de la antigua novia del Joker. La trama muestra la evolución en los diferentes años, observando los progresos de la reclusa y terminando con la concesión de su respaldo (Pardo y Monje 2016: 37).

Poco después, se da una gran oportunidad perdida, el intento de Gail Simone de introducir a Harley como personaje fijo en la colección Birds of Prey. Guionista que había liderado una excelente etapa en Wonder Woman (Cañas Pelayo 2017: 88), generaba expectación que aportaciones podía realizar con el personaje, pero su abandono de la cabecera a los cuatro meses lo impidió. 
Como en anteriores ocasiones, las series animadas de la franquicia ofrecían fórmulas para aplicar con éxito en las viñetas. Tras la buena acogida de Batman: The Animated Series, Bruce Timm y su equipo se embarcaron en Batman Beyond una saga futurista donde un envejecido Bruce Wayne entrenaba a un nuevo discípulo para ayudar a una Gotham con grandes avances tecnológicos y mucha corrupción (Hernando 2005: $36-38)^{9}$.

Sin embargo, pese a la buena aceptación de esa versión futura de Batman, la audiencia seguía con interés que prosiguiera la serie madre, especialmente con aquellos personajes que más aceptación lograron. Directamente a la red se lanzan los cortos animados de Gotham Girls, donde el protagonismo será ejercido por Catwoman, Harley Quinn, Batgirl y la detective Renée Montoya (Hanley 2017: 122-132).

La buena acogida de los mismos confirmaba que la óptica femenina sobre Gotham ofrecía un enfoque rico y novedoso, algo respaldado por las críticas elogiosas que poseyeron los capítulos donde la narración principal recaía en estas figuras (Johnson 2017: 424-426). Con esa inspiración, Dini y el dibujante Guillem March lanzan Gotham City Sirens en verano de 2009, donde el peso de la misma recae en el triunvirato formado por Poison Ivy, Catwoman y la propia Harley.

Otra aparición reseñable la encontramos el año anterior a dicho lanzamiento en Joker, un cómic de tono adulto firmado por el guionista Brian Azzarello y Lee Bermejo. Se trataba de una historia vista bajo la óptica del payaso e intentando dar un tono más

\footnotetext{
${ }^{9}$ Harley no aparecería directamente en dicha serie, aunque se mencionaba que había abandonado su actividad delictiva. Sí aparece por partida doble en El regreso del Joker (2000), largometraje derivado de la serie. Por un lado, en flashbacks donde colabora con el Joker para capturar a Tim Drake, ayudante de Batman. Asimismo, como una ya reformada ciudadana de Gotham preocupada porque sus nietas parecen haber heredado su habilidad para meterse en líos con la ley. El doblaje de Arleen Sorkin como Harley y Mark Hamill como Joker, al igual que en la serie animada, fue considerado uno de los grandes aciertos del film (Beatty 2004).
} 
realista al personaje. Dentro del sello DC Black Label, presentará a una Harley convertida en guardaespaldas del criminal, además de lucir un traje de cuero que recuerda a su uniforme de la serie animada, el cual utiliza en un sórdido local nocturno al que acuden mafiosos. Como han indicado análisis previos (Fente y Fernández 2016: 31), se echa de menos un mayor protagonismo del personaje, quien además muestra aquí su primera versión taciturna, sin apenas diálogo.

\section{La icónica imagen de la anarquía}

La compañía de videojuegos Rocksteady Studios lanzó en 2009 Batman: Arkham Asyum, una recreación a este medio de muchos de los pilares de Batman. Uno de los grandes éxitos del mismo fue lograr el fichaje de Arleen Sorkin y Mark Hamill como Harley y el Joker. En un contexto donde se la estaba desatendiendo en los cómics, el mundo del videojuego permitió a una nueva generación interesarse por la personalidad de aquella antiheroína.

Las buenas ventas de Arkham Asylum llevaron a secuelas igualmente lucrativas, lo cual beneficiaba a los protagonistas de la mismas, convenciéndose Warner Bros de que debían seguir haciéndose proyectos con Harley. Uno de los aspectos negativos de su andadura en esas plataformas fue la innecesaria sexualización que se hacía de su vestimenta. Al igual que Catwoman o Poison Ivy, siempre habían sido personajes con poder de seducción y sensualidad, pero en este medio se tornaban mujeres objetos (Hanley 2017: 191-192).

Habríamos de esperar a Injustice: Gods Amongs Us para un mejor tratamiento en el año de 2013. Disponible para compañías de tanto alcance como Sony, Nintendo y Microsoft, además de móviles (Fente y Fernández 2016: 38). El argumento del mismo 
generó una gran expectación entre el público aficionado al género superheroico, puesto que planteaba un futuro alternativo de los personajes de DC donde todo había cambiado dramáticamente.

Sin entrar en excesivos detalles, baste resumir que todo se iniciaba con la decisión de un héroe como Superman de asesinar a sangre fría al Joker. El motivo era el enloquecimiento que le producía al primero la trágica muerte de su pareja, Lois Lane, a manos del delincuente de Gotham. Batman encabezaría una resistencia de otras heroínas y héroes que juzgaban que nunca se debía cruzar ese umbral de tomar la justicia por su mano. En contra, Superman recibía otras alianzas que comulgaban con imponer esos métodos a cambio de proteger a las personas inocentes.

Sorprendía poco que una defensora del libre albedrío como Harley Quinn terminase enterrando el hacha de guerra con Batman para ayudarle en su causa. El doblaje en las escenas de vídeo de Tara Strong fue uno de los más apreciados del videojuego, quien supo dotar a Harley ironía y carisma, recordando a Sorkin. Además, en una historia de excesos donde Superman y Batman parecían incapaces de hallar el término medio, una de las protagonistas que más simpatías despertaba era la antigua novia del Joker, quien, además, aquí se tomaba la revancha contra otra versión del payaso (Fente y Fernández 2016: 38).

Tom Taylor, guionista que recibió el encargo de hacer una adaptación a las viñetas del juego, también apostó por esa cesión de galones a la ex villana, quien ahora era un referente en la comunidad de jugadores/as, yendo mucho más allá del mero objeto de deseo masculino, convirtiéndose en una líder por pleno derecho. 
Paralelamente, en septiembre de 2011, la situación de Harley Quinn en la industria del cómic iba a iniciar una gran etapa. Aprovechando la fama alcanzada en los videojuegos, surgió una nueva colección y, lo que más importante, con una pareja escritora que tendría continuidad para llevarla a nuevas cotas: nos referimos al trabajo de Amanda Conner y Jimmy Palmiotti (Fernte y Fernández 2016: 32).

Los primeros compases confirman la absoluta separación entre Harley el Joker, buscando colocar a la primera en nuevos escenarios. Esto entraría en cierta contradicción con sus apariciones en El Escuadrón Suicida ${ }^{10}$, uno de los grupos más pintorescos del universo DC, donde el escritor Adam Glass había actualizado de nuevo el origen de la protagonista, donde se omitía la participación de Poison Ivy y volvía deber su transformación enteramente al Joker.

Lejos de desanimarse por esa circunstancia, Amanda Conner tomó nota de cuáles eran los caminos por explorar, esperando una nueva oportunidad de trabajar con Harley que surgió a finales de 2013. Con 100.000 ejemplares vendidos en la primera tirada, los siguientes meses confirmaron su buen rumbo.

Con una estética que bebía mucho del surrealismo y romper la cuarta pared para interactuar con la persona lectora, se trataba de una colección muy original y alejada de los tópicos del género superheroico. Su número 0 fue una declaración de intenciones de este tono metaficcional, con Harley reflexionando en un soliloquio cuál había sido su impacto en los distintos formatos y qué podía ofrecer a la audiencia para mantenerse de moda (Fente y Fernández 2016: 33).

\footnotetext{
${ }^{10}$ Clásico grupo del universo DC donde personas superpoderosas con antecedentes accedían a realizar misiones de gran peligro para reducir su condena.
} 
El juego que plantea Amanda Conner lleva al siguiente paso, donde la propia protagonista se embarca en la elección del cuerpo artístico en la editorial que mejor podría captar su personalidad. Naturalmente, termina decantándose por Conner y Palmioti, además de escoger como dibujante a Chad Hardin. En resumen, un experimento plagado de ironía que daba un nuevo tono, algo confirmado en las siguientes entregas con la decisión de mudarse a Coney Island, necesario alejamiento de Gotham.

Generando una gran complicidad con la persona lectora, particular mención merece la idea de Conner y Palmioti de llevarla a la comic-con de San Diego, uno de los encuentros más populares de las personas aficionadas al cómic. El comportamiento de Harley es una aguda reflexión humorística sobre las ventajas e inconvenientes de la pasión. Desde su emotivo encuentro con sus creadores, Dini y Timm, pasando por algunos momentos hiperbólicos donde ella misma sufre acoso de fan boys y fan girls radicales. Es un encuentro con su propio reverso del espejo, puesto que ella misma comenzó su andadura así (Fente y Fernández 2016: 34).

Uno de los grandes atractivos de la propuesta y que explican su alcance es una constante improvisación que impide repetirse, teniendo la anarquía como principal denominador común. Con motivo de su vigésimo quinto aniversario, crearon los especiales Harley's Little Black Book, donde se rescataban importantes encuentros de la heroína con otros iconos de DC. El primer número es el más significativo al coincidir en Londres con Wonder Woman, a la cual agradece haberle servido como fuente de inspiración para su emancipación. 
En esta fase encontramos una de las claves que justifican la tesis del presente artículo: la transformación de una protagonista que había comenzado bajo la sombra de sus compañeros masculinos hasta desempeñar un papel clave en una visión feminista del medio. Si Wonder Woman encarnaba los principios del movimiento, Harley arroja una visión de rebeldía y superación desde un punto de partida tan dramático como ser la victima de una relación plagada de abusos.

Con esos precedentes no resulta nada extraño que Harley fuese uno de los miembros escogidos por la Warner Bros para la película Escuadrón Suicida (2016).

\section{Estrenos y perspectivas de futuro}

David Ayer dirigió el film que llevaba a la gran pantalla a un peligroso supergrupo de criminales forzados por el gobierno a realizar misiones de alto riesgo. $\mathrm{Si}$ bien obtuvo una recaudación en taquilla satisfactoria, la versión presentada fue acusada en varios aspectos de haberse desviado de la idea original en las viñetas, especialmente de los años del guionista John Ostrander ${ }^{11}$, el periplo más clásico de dicha colección.

La obra plantearía aspectos positivos y negativos con respecto al tratamiento de Harley Quinn. Entre los primeros, Margot Robbie, la actriz escogida para encarnarla, mostraría una gran complicidad con el personaje, hasta el punto de manifestar su interés en producir una película sobre ella. Asimismo, en un curioso paralelismo con los cómics, compartió la popularidad en el grupo con el Deadshot de Will Smith.

\footnotetext{
${ }^{11}$ Con ayuda del propio Ostrander en el argumento, las personas aficionadas a este grupo juzgaron más fiel la cinta de animación Escuadrón Suicida: Consecuencias infernales (2018). Harley tuvo un papel sobresaliente en la misma, destacando que Tara Strong volvió a darle voz. Cuatro años antes, el Escuadrón hizo su primera aparición animada en Batman: Asalto a Arkham, donde personajes como Deadshot o la propia Harley robaban el protagonismo al mismísimo Murciélago.
} 
Por otro lado, María Fente y Norman Fernández han subrayado los riesgos que entrañó esta actualización a la gran pantalla de la tóxica relación Joker-Harley (2016: 40-43). En su análisis, muestran claramente cómo Mad Love trazó con sutileza un tema tan delicado como el maltrato, creando un personaje capaz de superar semejante situación y evolucionar.

En la cinta observamos que se trata de plantear que ambos escenificarían un romance libre y muy abierto, de dos personas que se aceptan tal y como son. Eso habría sido un interesante giro de guión, pero en lo observado en las escenas de flashback sigue existiendo esa conversión forzada por parte del segundo, quien llega a aplicar electroshock a su supuesta enamorada.

Mucho más adulto hallamos el relato Caballero Blanco, una mini-serie de DC ambientada en un posible futuro de la antigua Batman: The Animated Series. En ella, el Joker recupera la cordura y asume la identidad civil de Jack Napier. Alejado de la demencia y conservando su astucia, es capaz de trazar un plan legal para vencer a Batman, acusándole de brutalidad y ser parte del problema antes que de la solución. El guión plantea situaciones especialmente interés con Harley, quien ya hace tiempo que ha guardado su antiguo disfraz y ejerce como la doctora Quinzel (Murphy 2019).

Es la primera vez que tenemos un diálogo de un cuerdo Napier que es consciente de cuál fue la situación en la que colocó a su compañera. Lejos de perder interés sin el rol de Harley Quinn, Quinzel se revela como el personaje más empático de toda la saga, capaz de entender también el papel de Batman, con quien mantiene una conversación donde le agradece la ayuda que le prestó para reinsertarse. Por su lado, Bruce Wayne 
reconocerá que ella posee una mejor visión sobre esta lucha que los propios antagonistas.

Recientemente, contamos con estudios que ponen de relieve como Harley Quinn sirve como análisis perfecto de los distintos roles de género (Romero Gallardo y Arteaga Botello 2017: 287-319), además de plantear debates de sumo interés. ¿Es su rebeldía un paso adelante que mostrará un nuevo tipo de protagonista femenina en los medios de masas? ¿O supone acaso un mero ejercicio estético, pero que no cuestiona en realidad la necesidad de superar los estereotipos asociados a la pasividad femenina en el cómic superheroico?

A lo largo de estas páginas, hemos pretendido mostrar como Mad Love supuso el punto de inflexión que permitió a la protagonista enriquecer su personalidad y presentar una realidad tradicionalmente tapada en las viñetas: el crecimiento y emancipación de una persona que ha sufrido una relación tóxica. Planteamientos como el de la guionista Amanda Conner confirman que sus posibilidades van mucho mas allá de su pasado vínculo con el Joker, si bien es un riesgo frecuente que otras visiones incidan en reducirla a esa escala.

Se expone, en definitiva, a un personaje ya plenamente consolidado y que aquí ofrece una madurez que la hace aventajar en esa faceta a los dos antagonistas masculinos, Batman y el Joker, sumergidos en una partida de aniquilación mutua, lo cual permite a la doctora, por su experiencia en tales lides, entender que deben cerrarla antes de llevarse mutuamente al abismo. 
Con el significativo título de Birds of Prey (And The Fantabulous Emancipation of one Harley Quinn) ${ }^{12}$, el nuevo estreno de un film sobre Harley Quinn parece que intentará abrir asimismo esas puertas liberadoras para la heroína anárquica en la gran pantalla.

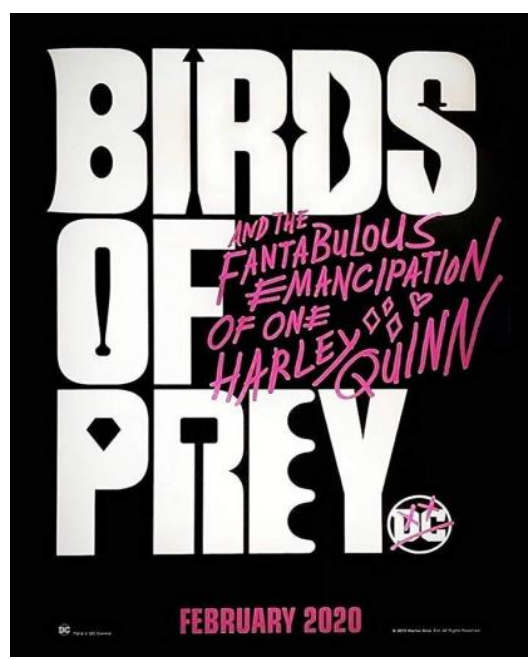

Fig. II. Cartel promocional de Birds of Prey (estreno en febrero de 2020)

\section{Referencias bibliográficas}

Álvarez, Raúl. 2018. Batman, el héroe: La trilogía de Christopher Nolan. Madrid: Rialp.

Barba, Shelley E. y Perry, Joy M. 2017. The Ascendance of Harley Quinn: Essays on DC's Enigmatic Villain. Jefferson: McFarland \& Company.

Beard, Jim. 2011. Gotham City 14 Miles: 14 Essays on Why the 1960s Batman TV Series Matters. Edwardsville: Sequart Organization.

Beatty, Scott. 2004. Batman Beyond: The Animated Series Guide. Londres: Dk Pub.

\footnotetext{
12 Previamente hallamos la serie Birds of Prey (2002), donde una Harley muy desvirtuada era la principal antagonista de las heroínas, sin excesivo éxito de audiencia.
} 
Cocca, Carolyn. 2016. Superwomen: Gender, Power, and Representation. New York: Bloomsbury.

Desris, Joe. 2016. Batman: Facts and Stats from the Classic TV Show. Londres: Titan Publishing Group.

Dini, Paul y Kidd, Chip. 2016. Batman Animated. New York: HaperCollins Publishers.

y Timm, Bruce. 2015. Batman Adventures: Mad Love Deluxe Edition HC. Burbank: DC Comics.

Burbank: DC Comics.

2016. Batman: Harley and Ivy: The Deluxe Edition.

Fente, María y Fernández, Norman. 2016. "Harley Quinn: Parte 2”. Dolmen: Revista de información sobre cómic 255: 31-43.

Goodrum, Michael, Prescott, Tara y Smith, Philip. 2018. Gender and the Superhero Narrative. Mississippi: University Press of Mississippi.

Hanley, Tim. 2016. Investigating Lois Lane: The turbulent history of the Daily Planet's ace reporter. Chicago: Chicago Review Press.

2017. The many lives of Catwoman: The felonius history of a feline fatale. Chicago: Chicago Review Press.

Hernando, David. 2004. Batman: el resto es silencio. Palma de Mallorca: Dolmen. 2005. "Bruce Timm”. Dolmen Monográficos 7: 1-98.

. 2014. Batman: Serenata nocturna. El origen del Caballero Oscuro. Barcelona: Timunmas.

Johnson, Ken. 2017. The Man Who Watched Batman: Ultimate Edition: An in depth Guide to Batman: the animated series. Scotts Valley: CreateSpace Independent Publishing Platform.

Lepore, Jill. 2015. The secret history of Wonder Woman. Londres: Scribe Publications.

Morris, Jon. 2018. League of Regrettable Sidekicks. Philadelphia: Random House USA Inc.

McCausland, Elisa. 2017. Wonder Woman: El feminismo como superpoder. Madrid: Errata naturae.

Murphy, Sean. 2019. Batman: Caballero Blanco. Barcelona: ECC Ediciones.

Nicholson, Hope. 2017. The Spectacular Sisterhood of Superwomen. Washington: Library of Congress Cataloging in Publication. 
Nolen-Weathington, Eric (ed.). 2012. Modern Masters Volume 3: Bruce Timm. Raleigh: TwoMorrows Publishing.

O’Neil, Dennis (ed.). 2008. Batman Unauthorized: Vigilantes, Jokers, and Heroes in Ghotham City (Smart Pop Series). Dallas: BenBella Books.

Pardo, Jordi T. y Monje, Pedro. 2016. "Harley Quinn: Parte 1". Dolmen: Revista de información sobre cómic 254: 33-39.

Romero Gallardo, Michelle Vyoleta y Arteaga Botello, Nelson. 2017. "Harley Quinn y la purificación de la iconicidad femenina rebelde". Culturales 2: 287-319.

Rubio Méndez, María. 2017. Comunidad, género y videojuegos. Salamanca: Universidad de Salamanca.

Salazar, Eduardo. 2000. Los Vengadores: Guía de lectura. Madrid: Imágica Ediciones.

Serradilla, Eduardo. 2008. Monográficos Dolmen: Jim Lee 15: 1-98. 